\title{
Metaplastic Meningioma
}

National Cancer Institute

\section{Source}

National Cancer Institute. Metaplastic Meningioma. NCI Thesaurus. Code C6907.

A WHO grade I meningioma characterized by the presence of a prominent mesenchymal component. The mesenchymal component may be osseous, cartilaginous, myxoid, lipomatous, or a mixture of mesenchymal elements. 